\title{
The Lobster Game: Experiential learning of system dynamics through serious gaming
}

\author{
$\underline{\text { R.G. Richards }}^{a, b}$ and N. Jagdish ${ }^{c}$ \\ ${ }^{a}$ School of Business, The University of Queensland, Brisbane, QLD 4072, Australia, ${ }^{b}$ Coastal and Marine \\ Research Centre, Griffith University, Gold Coast Campus, QLD 4222, Australia, ${ }^{c}$ BTN Pte Ltd, Singapore. \\ Email: r.richards@business.uq.edu.au
}

\begin{abstract}
We showcase a serious game (The Lobster Game https://lobstermodel.web.app/) that was developed to help meet the learning objectives of a course (System Dynamics) taught at the University of Queensland Business School (UQBS), Queensland, Australia. This paper presents the motivation for gamifying a system dynamics model and the mechanics of the system dynamics model itself. The Lobster Game is a computer-based app (PC, Mac) aimed at helping students enrolled in this course to better understand and apply the concepts of systems thinking and system dynamics. This app was also developed with the capacity to be used in courses from other disciplines within the UQBS including International Business, Supply Chain Management and Sustainability. The motivation for using a serious game approach was its capacity to foster experiential activity-based learning, moving away from the standard didactic approach. Serious games, which we broadly define here as 'video games with a learning purpose', are growing in global popularity, reflecting the increasing ubiquity of video gaming, the accessibility and utility of powerful video game development software, and the demand for active-based education. The scope was to represent a well-managed fishery dominated by international exports, where fishing effort was regulated but also strongly influenced by market dynamics. The result is a system dynamics model (SDM) developed in Unity3D that draws heavily upon elements of the Australian rock lobster fishery, particularly the western rock lobster (WRL) fishery. Features incorporated into the underlying SDM is an international supply chain of live lobsters, the use of fishing quotas (catch-quota controlled) and supply-demand-price dynamics. The SDM is dominated by balancing loops (8) that provide strong regulating effects on this social-ecological fishery system through ecological (carrying capacity), economic (supply-demand-price, CPUE) and regulatory (quota) feedbacks. Assessment of the SDM's performance involved standard system dynamics tests of unit consistency checks, extreme condition testing, conservation of material and behaviour consistency checks. Consistent with the stated learning objective and its specific application in system dynamics education, The Lobster Game contains a story that provides the narrative for the system, and a model, that provides the numerical playground for the system. The Lobster Game was completed June 2021 and will be introduced to students during second semester (July October), 2021.
\end{abstract}

Keywords: The Lobster Game, Serious games, video game software, system dynamics, experiential learning, lobster fishery, UQ Cases 


\section{INTRODUCTION}

This paper showcases The Lobster Game (https://lobstermodel.web.app/), which combines system dynamics modelling and video gaming technology to provide an experiential learning tool for tertiary-level education (a serious game). This paper presents the motivation for gamifying a system dynamics model and the mechanics of the system dynamics model itself.

The Lobster Game was developed in 2021 to meet learning objectives of a system dynamics course taught at the University of Queensland Business School (UQBS) - Understanding and applying the tools of systems thinking and system dynamics. It was also developed with the capacity to be used in other disciplines (e.g. international business, supply chain management, fisheries management, natural resource decision-making).

System dynamics modelling, and more broadly, the systems method (Sterman, 2000) provides a formal modelling framework that is focused on the role of feedback loops and delays in determining system behaviour. It has had widespread application in a diverse range of topics (e.g. Richards \& Smith, 2017; Elsawah et al., 2017 ) and is particularly noteworthy for facilitating participatory involvement of end-users (Richards \& Smith, 2017).

System dynamics modelling has often embraced a serious games ethos, through participatory modelling (Richards et al., 2015), storytelling (Richards \& Smith, 2017) and flight console styled user interfaces (Sotaquirá-Gutiérrez et al., 2016).

Serious games are increasingly being used to provide experiential and activity-based environments for students, end-users and policy makers (e.g. Catalano et al., 2014; Anderson et al, 2017). They are premised on experience-based learning (Catalano et al., 2014), helping to foster problem solving skills, participatory engagement, communication and decision-making (Catalano et al., 2014; Castronova \& Knowles, 2015; Wesselow and Stoll-Kleemann, 2017).

The ubiquity of computers, the rapid rise in computing power (e.g. Moore's Law) and in video game development software, coupled with the global popularity of video gaming means that serious games via video gaming is at the frontier of developing and applying these learning tools. This is evidenced by the diverse range of fields where serious games have been used (Castronova \& Knowles, 2015; Anderson et al., 2017).

The efficacy of using serious games for active learning is promising and a key is how they motivate the 'endusers' to play and learn (de Freitas, 2006) through the sense of challenge, game realism and opportunities for the players to explore and discover (deFreitas, 2006). Furthermore, the type of game itself is important in terms of the specific learning objectives that are to be met (Buchanan et al, 2011).

\section{UQ CASES}

The Lobster Game is the eighth case developed for the University of Queensland's UQ Cases app project. UQ Cases is an app developed for delivery of single player and multiplayer simulation games (teaching cases) on PC and Mac computers. The seven cases developed prior to The Lobster Game are hosted within the UQ Cases app and contain three components:

- Story: provides the narrative of the case and a description of the system using a combination of text and images.

- Simulation: provides access to the system dynamics model where the user can test different interventions for the case.

- Quiz: Multiple choice questions designed to reinforce learning from the case.

The Lobster Game is distinguished from the other 7 cases in that it is a standalone case (i.e. not accessed through the UQ Cases App), is run through the browser rather than as a locally-run executable on a computer and does not include a quiz component.

\section{ROCK LOBSTER FISHERY}

This section provides broad detail about the state of the rock lobster fishery in Australia to provide context for the system dynamics model that underpins The Lobster Game.

The Australian rock lobster fishery is worth approximately $\$ 752$ million (AUD) per annum (Mobsby et al., 2020). Prior to the Covid-19 pandemic, the total Australian rock lobster market, was dominated (ca. $94 \%$ ) by 
live exports to China (Mobsby et al., 2020), facilitated by the signing of the China-Australia Free Trade Agreement (ChAFTA) in 2015 (DFAT, 2015). Rock lobster fisheries management in Australia is catch-quota controlled through a total allowable commercial catch (TACC), with stock assessment and management based on level of puerulus settlement (Caputi et al., 2015). The export supply chain involves the transport of catch to a purpose-built holding infrastructure located near the international airport (Caputi et al., 2015). Here they stay until they are ready to be air-freighted to overseas markets. When they arrive at their destination, they spend time in quarantine before being sold to consumers. The market price of lobsters is dependent on supply-demand dynamics as typified by the effect on pricing brough about by the recent Covid-19 disruptions to both supply and demand (ABC 2020).

\section{SYSTEM DYNAMICS MODEL DEVELOPMENT}

System dynamics was selected over agent-based modelling as the underlying simulation model. Rationale for scaffolding on a systems framework is that (1) it provides a structured approach for integrating crossdisciplinarian (economics - social - ecological) components; (2) it produces tangible outputs (causal loop diagram, stock and flow model) in addition to the 'game'; (3) the model that is the 'engine' for the game can be quickly developed and tested in system dynamics-specific software (e.g. Stella Architect); (4) it aligns with the learning objectives of the system dynamics course where this game will be used; and (5) the author's greater familiarity of system dynamics (including in developing the UQ Cases) over ABM. Stella Architect (www.iseesystems.com) for building the causal loop diagram (CLD) and the stock and flow system dynamics model. Unity3D game engine (https://unity.com/) was used for building the game.

\subsection{Model description}

The underlying system dynamics model (SDM) draws upon elements of the Australian rock lobster fishery, particularly the western rock lobster (WRL) fishery. However, it was not the aim of The Lobster Game to precisely replicate any specific fishery and therefore the underlying model is not a precise simulation of an existing fishery (e.g., WRL) per se.

\subsection{Model conceptualisation}

Development of the SDM started with conceptualization of the model using a CLD (Figure 1). This CLD contains one reinforcing loop and eight balancing loops. The reinforcing loop (R1) represents the loop between lobsters and their puerulus that promotes exponential growth of the lobster population. The population dynamics is 'balanced' by the carrying capacity effect (B1), which limits the growth of the population as it approaches, or exceeds, the carrying capacity. Loop B2 reflects the balancing relationship between catch, catchability, and lobster population i.e., as lobster is caught, the population decreases, which lowers their 'catchability', represented by the catch per unit effort (CPUE).

Puerulus abundance is used in the SDM as the basis of stock assessment, which is then used for setting the annual quota for the TACC (B3) and fishing licences (B5). Both loops contain information delays (double perpendicular lines across the connection) to reflect delays in measuring, reporting, and acting on stock assessment. Balancing loop B4 reflects depletion of the available catch quota through catch, that is, as the available quota decrease, fishing effort will decrease.

Feedback loops B3 - B7 are balancing effects that limit fishing effort through available quota (B3, B4), fishing licences (B5), CPUE (B6) and price-supply dynamics (B7).

Balancing loop B8 accounts for price effects on demand (using substitute pricing) and integrates with B7 to reflect the price-supply-demand dynamics. Price-supply dynamics is provided by loop B7, where increased supply of lobsters is assumed to have downward pressure on price, which reduces fishing effort and consequently supply. Loop B8 provides the price-demand dynamics, where demand places upwards pressure on price, which pushes demand down. The effect of price on demand is dependent on the comparative relationship between rock lobster price and the price of a substitute product, which could be rock lobsters from a competitor country, or could be a similar product (e.g., swimmer crab). 
The CLD has three input variables: substitute price, carrying capacity, transit time. Transit time reflects the time for product to transit the supply chain and includes transport time (domestic and international), pre-export storage, and international quarantine.

\subsection{System dynamics model}

The SDM was developed using a stock and flow modelling arrangement (Sterman, 2000). Figure 2 illustrates the five sub-modules that constitute the SDM and how they interconnect. This SDM was developed directly from the CLD (Figure 1).

Licencing \& Quotas: This sub-module is shown in Figure 3. It comprises three stocks (Licences, Stock Assessment, Available Quota). The Stock Assessment is calculated from the puerulus (Larval) stock calculated in the population sub-module, which is then used to calculate the annual quota (quota amount). The Available Quota stock is 'cleared' and then 'set' to the quota amount, controlled by the Quota Clock using STELLA's built-in PULSE function. The quota amount is also used to calculate the number of fishing licences

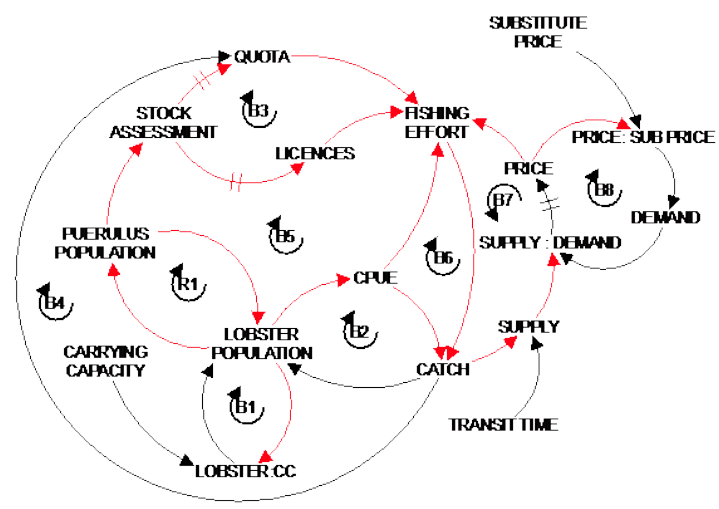

Figure 1. Causal loop diagram of the lobster model. Red connections are positive polarities black connections are negative polarities. Parallel lines across connections indicate information delays between connected variables. (Licences) using a goal-seek model structure (Sterman, 2000).

Lobster population: Uses a three life-stage (Larval [puerulus], Juveniles, Adults) population model. The death rate of the juvenile and adult stages is influenced by a population carrying capacity, employing a dimensionless multiplier as a graphical function. Dimensionless multipliers are often used in system dynamics modelling to adjust the value of a response variable for a given causal effect (Maani and Cavana, 2007) and is a common feature throughout this SD model. The birth rate of the Larval life-stage is calculated as a product of the current Adult lobster population. Movement between life-stages is determined by residence time (planktonic time, maturation time). Larval diffusion (inflow) is included to allow the population to recover even if the entire lobster population is wiped out. This module contains the balancing feedback of catch on catchability (CPUE - B2)

Fishing effort: Incorporates the multiplicative effects of available quota, CPUE, storage, and price on total (fleet) fishing effort. All effects are applied using dimensionless multipliers, where the input variable is normalised to a reference (or 'normal') value (see Maani and Cavana, 2007). For example, the effect of price of fishing effort is uses the ratio of price:normal price.

The effect of CPUE (catch-per-unit-effort) on fishing effort is assumed to follow a logarithmic response curve, where increase CPUE results in greater fishing effort. This effect is contextualised as a cost (higher operational cost at lower CPUE), which is the rational for using a positive relationship between these two variables. Quota is assumed to have no effect on fishing effort until the available quota level falls to below the Normal Quota' amount. Below this threshold, the effect is to quickly decrease fishing effort towards zero (and when the available quota $=0$, fishing effort $=0$ ). The effect of price on fishing effort is assumed to follow a s-shape growth curve. When the price is equal to the 'normal price', there is no effect on fishing effort. When price $>$ normal price,

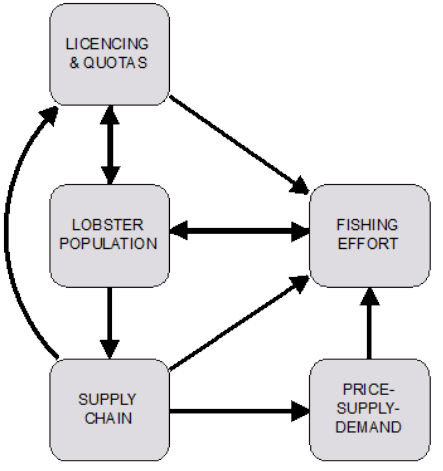

Figure 2. Sub-module diagram of the system dynamics model the effect is to increase effort, and when price $<$ normal price, the effect is to decrease price. Finally, storage represents the limiting effect of the holding infrastructure (located near the international airport) on fishing effort when it approaches its capacity.

Supply chain: The supply chain module simulates the movement of live lobsters from the fishing vessels (landed), transport to, and stored at, export holding infrastructure (storage), and stored at quarantine facilities 
(quarantine) at the destination country. Within this sub-module, the holding infrastructure has a limiting effect on transport of landed lobster. Storage at each point along the supply chain (Landed, Stored, Quarantine) corresponds with a mortality rate, which causes live lobsters to be removed from the supply chain as waste. Mortality rates are highest for Landed and Quarantine stocks, reflecting that these storage points are not designed for long-term storage of live lobsters (as opposed to the holding infrastructure, Stored).

Price-Supply-Demand: The economic dynamics for rock lobsters is based on a standard of price-supplydemand model that uses dimensionless multipliers and a goal-seek model structure (e.g. Richards and Smith, 2017). Only the rock lobsters leaving quarantine (supply chain sub-module) represent the 'supply' and

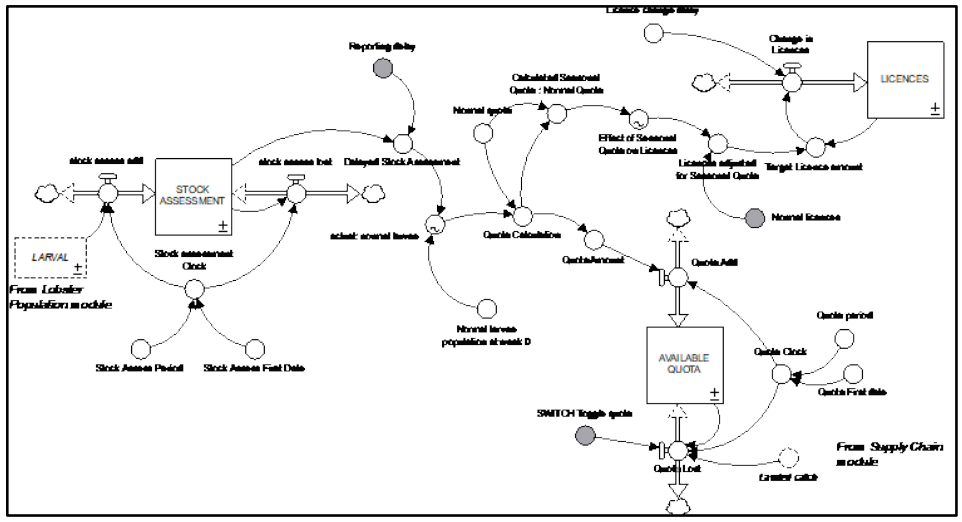

Figure 3. Licencing and Quotas sub-module therefore lobsters that die along the supply chain do not contribute to revenue. The demand is adjusted for both the rock lobster price and the price of an unspecified substitute product. The supplydemand ratio is then used to set an expected price, which becomes the 'goal' of the goal-seek model.

The model is parameterised to be at dynamic equilibrium when run using default settings (time horizon $=5$ years). All submodules contain a selection of interventions that can be used to disrupt the model from equilibrium. For example, the quarantine time (supply chain sub-module) can be increased to simulate delays in the quarantine time, which can lead to loss of stock. The rationale for parameterising the model for equilibrium conditions reflects the key learning objective of Understanding and applying the tools of systems thinking and system dynamics. Specifically, understanding how shocks to a system can cascade throughout a system, and how system feedback loops can perpetuate (reinforcing) or mitigate (balancing) impacts.

The SDM's performance was assessed using standard system dynamics tests of unit consistency checks, extreme condition testing, conservation of material and behaviour consistency checks (Maani and Cavana, 2007).

\section{THE LOBSTER GAME}

\subsection{Development process}

This section briefly outlines the gamified system dynamics model (The Lobster Game, https://lobstermodel.web.app/) to supplement the primary focus on the systems modelling outlined in the previous section.

Development of the game followed a process of pre-alpha, alpha, beta testing before finalisation. The scope for The Lobster Game case was to represent a well-managed fishery that is dominated by international export, and where fishing effort is regulated but also strongly influenced by market dynamics (supply-demand-price).

Three ideation sessions were held with three academics at the University of Queensland who had expertise in International Business, Supply Chain management and seafood sustainability. During these sessions, a divergent activity was used to scope out a range of potential features for The Lobster Game, including its application in teaching (learning objectives), the spatial and organisational scopes, time horizon, decision rules, game logic, visual representation $(2 \mathrm{D}, 2.5 \mathrm{D}, 3 \mathrm{D})$ and modelling approach (agent-based, system dynamics, hybrid).

The second stage of development of the game structure, drawing upon the ideation sessions, the literature on Australia's rock lobster fisheries and on the features of the existing suite of cases within the UQ Cases (an example of the latter was the decision to make The Lobster Game a standalone case to increase its accessibility). 
Richards \& Jagdish, The Lobster Game: Experiential learning of system dynamics through serious gaming

\subsection{Game description}

The entry page to The Lobster Game (Figure 4a) contains two core options (Story or Simulation). The story page (or scene) (Figure 4b) presents information about the rock lobster model as a series of short paragraphs, supplemented by rich pictures. The aim is to provide sufficient detail about the system that the students understand how the system works. The simulation scene (Figure 4c) links the system dynamics model to a 2D visualization of the 'system'. This includes indicators for key variables (e.g. Price), UI to run the simulation and to access model controls and graphs. The game contains animation that is not linked to the simulation e.g. fishing boat movement, low-poly clouds, animated rendering of the sea - the rationale for including these animations is that it adds to the experiential aspect of the game.

Controls and output charts (Figure 4d) - UI Panel of controls, separated into types (e.g. regulatory). Controls are simplified to sliders or toggle switches. This is a departure from the other 7 cases (UQ Cases), where control variables were determined by specifying numeric values. The rationale is that sliders / toggle switches are easier to set. Output charts show comparative plots, enabling the effects of interventions (Controls) to be compared and contrasted with other scenarios.
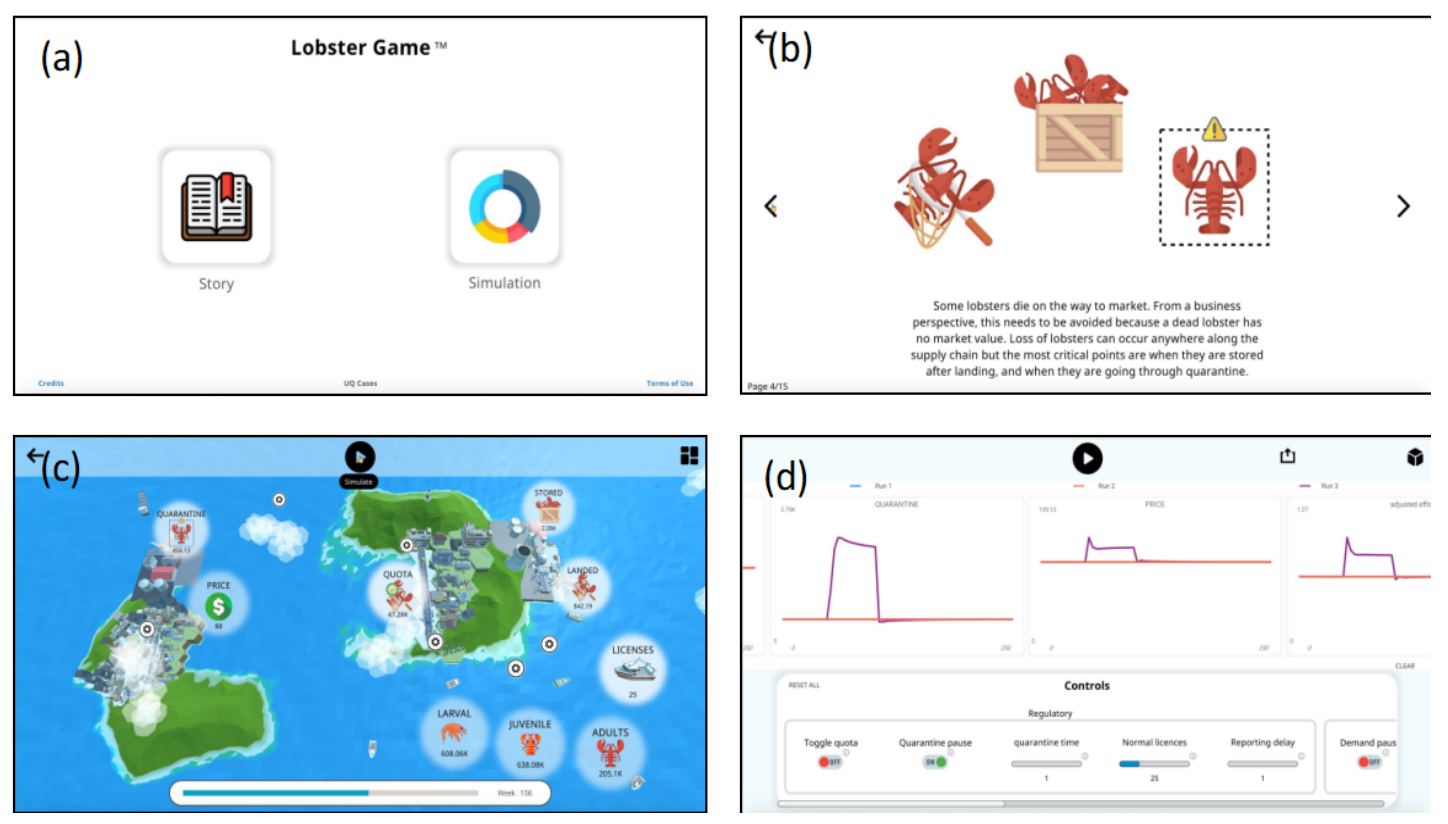

Figure 4. The Lobster Game: (a) Main menu screen, (b) The story, (c) Main simulation screen, (d) Input controls and output charts

\section{CONCLUSION}

We showcased here a game (The Lobster Game https://lobstermodel.web.app/) that melds together serious gaming and system dynamics modelling. This paper focuses predominantly on the underlying system dynamics model but also presents elements of serious gaming for context.

The core motivation for gamifying a system dynamics (SD) model was to help students enrolled in a system dynamics course (University of Queensland Business School) to better understand and apply the concepts of systems thinking and system dynamics. The motivation for using a serious game approach was its capacity to foster experiential activity-based learning, thus moving away from the standard didactic (rote learning) approach. The rationale for scaffolding the 'game' on a system dynamics model included that it matched the learning objectives of the system dynamics course where this game will be used.

The SD model draws upon elements of the Australian rock lobster fishery, particularly the western rock lobster (WRL) fishery. However, it was not the aim of The Lobster Game to precisely replicate any specific fishery and therefore the underlying SD model is not a precise simulation of an existing fishery per se. Development of the serious game followed a process of pre-alpha, alpha, beta testing, and involved ideation input from other academics from the University of Queensland Business School. 
Richards \& Jagdish, The Lobster Game: Experiential learning of system dynamics through serious gaming

The ability and capacity of The Lobster Game to advance learning by better understanding and application of systems thinking and system dynamics concepts has not been tested as this case has only just finished its development. Preliminary outcomes on pedagogical impact will be presented at the conference.

\section{ACKNOWLEDGMENTS}

This project was funded by the University of Queensland Business School (UQBS) as part of the UQ Cases project (\#614827). The authors acknowledge the support and contribution of the following UQBS academics: Dr Alexandra Kriz, Dr Anna (Anya) Phelan and Dr Henry Xu.

\section{REFERENCES}

ABC, 2020. https://www.abc.net.au/news/2020-01-25/coronavirus-puts-wa-crayfishing-industry-onhold/11900668 . Last accessed: 20 August 2021

Anderson, B., Coulter, S., Orlowsky, R., Ruzich, B., Smedley, R., Purvis, M., Learmonth, G.P., Gerling, G.J. 2017. Designing User Experiences for Policymakers in Serious Games in the Domain of Global Food Security.

Buchanan, L., Wolanczyk, F., Zinghini, F. 2011. Blending Bloom's Taxonomy and Serious Game Design. International Conference on Security and Management.

Caputi, N., de Lestang, S., Reid, C., Hesp, A., How, J. 2015. Maximum economic yield of the western rock lobster fishery of Western Australia after moving from effort to quota control. Marine Policy, 51, 452-464.

Castronova, E., Knowles, I. 2015. Modding board games into serious games: The case of climate policy. International Journal of Serious Games, 2(3), 41-62.

Catalano, C.E. Luccini, A.M., Mortara, M. 2014. Best Practices for an Effective Design and Evaluation of Serious Games. International Journal of Serious Games, 1(1).

de Freitas, S. 2006. Learning in immersive worlds. Report of the Joint information systems committee. Bristol, UK. http://www.jisc.ac.uk/media/documents/programmes/elearninginnovation/gamingreport_v3.pdf

DFAT, 2015. $\quad$ https://www.dfat.gov.au/trade/agreements/in-force/chafta/doing-business-withchina/Pages/guide-to-using-chafta-to-export-or-import Last accessed: 20 August 2021

Elsawah, S., Pierce, S.A., Hamilton, S.H., van Delden, H., Haase, D., Elmahdi, A., Jakeman, A.J. 2017. An overview of the system dynamics process for integrated modelling of socio-ecological systems: Lessons on good modelling practice from five case studies. Environmental Modelling \& Software, 93, 127-145.

Maani, K., Cavana, R., 2007. Systems Thinking, Systems Dynamics: Managing Change and Complexity. Pearson Education, Auckland, p. 278.

Mobsby, D., Steven, A.H., Curtotti, R. 2020. Australian fisheries and aquaculture outlook 2020. Australian Bureau of Agricultural and Resource Economics and Sciences (ABARES). March 2020.

Richards, R.G., Smith, C.S., 2017. SYSTORY - a story telling system dynamics model for addressing socioecological problems. MODSIM2017, 22nd International Congress on Modelling and Simulation. Modelling and Simulation Society of Australia and New Zealand, December 2017, Hobart, Australia.

Richards, R.G., Smith, C., Setianto, N. 2015. Opening SESAMME: An iPad-based application for developing socio- ecological models. MODSIM2015, 21st International Congress on Modelling and Simulation. Modelling and Simulation Society of Australia and New Zealand, December 2015, Gold Coast.

Sotaquirá-Gutiérrez, R., Ramírez-Rosales, F.E., Velásquez-Díaz, J.P. Robayo-Gómez, J.C. 2016. Improving the learnability of system dynamics simulation tools: a new design for a tablet device. Global Journal of Engineering Education. Volume 18, Number 2.

Sterman, J., 2000. Business Dynamics: Systems Thinking and Modeling for a Complex World. New York: Irwin McGraw-Hill. 